\title{
RESEARCH ON THE TREATMENTS AT SUB-ZERO TEMPERATURES OF THE SINTERED STEELS AND HARDENED IN OIL
}

\author{
Sandu DUBOVAN ${ }^{1, a^{*}}$, Traian POPESCU ${ }^{2, b}$, Lidia DUBOVAN ${ }^{3, c}$ \\ ${ }^{1}$ University of Craiova, Faculty of Mechanics, Drobeta Turnu-Severin, Romania \\ ${ }^{2}$ University of Craiova, Faculty of Mechanics, Drobeta Turnu-Severin, Romania \\ ${ }^{3}$ University of Craiova, Faculty of Mechanics, Drobeta Turnu-Severin, Romania \\ a* dubovans@yahoo.com , ${ }^{\mathrm{b}}$ trfilip@yahoo.com, ${ }^{\mathrm{c}}$ dubovanlidia@yahoo.com
}

Keywords: powder metallurgy, sintered steel, sub-zero treatment, cryo treatment

\begin{abstract}
The treatments of the hardened parts at low temperatures have like main goal the reducing of the amount of retained austenite through its transformation to martensite under the action of the strong contractions which occur in cryogenic environments. In the case of sintered steels such researches were achieved on a small scale. The paper presents results of research regarding the cooling in medium of dry ice and respectively of liquid nitrogen, for the three groups of sintered steels with structural carbon content of $0.54 \%, 0.75 \%$ and $0.92 \%$ sintered at $1150^{\circ} \mathrm{C}$ for $60 \mathrm{~min}$ and oil quenched.
\end{abstract}

\section{INTRODUCTION}

The heat treatments at low temperature are practiced because it's necessary like the steels to be brought into a state as close as possible to the entropic minimum so that at the maintaining for a long period it is producing the finishing and the leveling of the microstructures, simultaneously with structural transformation through which are realized the reducing of the retained austenite amount, and the formation of martensite. [1]

This ensures steels greater dimensional stability, increased hardness and thus increase the wear resistance. Depending on the thermal range in which these hardened parts were cooled this treatments are divided into three categories: cold treatment $(223 \div 193 \mathrm{~K})$, shallow cryogenic treatment $(193 \div 113 \mathrm{~K})$ and deep cryogenic treatment $(113 \div 77 \mathrm{~K})$. [2, 3, 4]

In the Powder Metallurgy such researches has been limited to studies on the effects of cold treatments applied to speed steel and cutting carbide plates. [5, 6, 7, 8, 9, 10,11]

In this framework was considered appropriate the study of heat treatments to cold (cold treatment and cryogenic treatment) applied to carbon sintered steels with carbon content of 0.54 $\% \mathrm{C}, 0.75 \% \mathrm{C}$ and $0.92 \% \mathrm{C}$ after their quenching into oil.

Comparative analyses were made concerning the content of martensite phase in these steels respectively regarding the microhardnesses evolution.

\section{MATERIALS AND EXPERIMENTAL PROCEDURE}

The sintered steels have been made by homogenizing a powder mixture consisting of iron powder type DWP 200, graphite and zinc stearate (denoted St-Zn in what follows, used as a binder and lubricant) in the following amounts:

$$
\begin{aligned}
& \mathrm{Fe}+0.6 \% \mathrm{Gr}+2 \% \mathrm{St} \mathrm{Zn} \\
& \mathrm{Fe}+0.8 \% \mathrm{Gr}+2 \% \mathrm{St} \mathrm{Zn} \\
& \mathrm{Fe}+1.0 \% \mathrm{Gr}+2 \% \mathrm{St} \mathrm{Zn}
\end{aligned}
$$

The homogeneous mixtures were compacted in mold by pressing one-sided with the pressure of $650 \mathrm{MPa}$ in the form of rectangular sample with the dimensions of $10 \times 10 \times 55 \mathrm{~mm}$.

The green compacts were sintered in the conditions specified in Table 1. After sintering (denoted S) the sintered samples were oil-quenched (denoted OQ) according to the process parameters 
specified in Table 2, to the cold treatment (denoted Z) in the conditions specified in Table 3, and finally subjected to the shallow cryogenic treatment (denoted $N$ ) in the conditions specified in Table 4. [12]

Table 1. Applied Sintering Conditions

\begin{tabular}{ccc}
\hline \hline & Parameters & Designation \\
\hline \hline Sintering Temperature & $1150^{\circ} \mathrm{C}$ & \\
Time at Temperature & $60 \mathrm{~min}$ & $\mathrm{~S}$ \\
Atmosphere & Argon & \\
Cooling Rate & $5.8^{\circ} \mathrm{C} / \mathrm{min}$ & \\
\hline
\end{tabular}

Table 2. Applied Quenching Parameters

\begin{tabular}{ccc}
\hline \hline & Parameters & Designation \\
\hline \hline Austeniting Temperature & $860^{\circ} \mathrm{C}$ & \\
Time at Austeniting Temperature & $15 \mathrm{~min}$ & \\
Atmosphere & Argon & \\
Quenching & Oil & OQ \\
\hline
\end{tabular}

Table 3. Cold Treatment Conditions

\begin{tabular}{ccc}
\hline \hline & Parameters & Designation \\
\hline \hline Cold treatment - Temperature & $197 \mathrm{~K}$ & \\
cooling medium & dry ice & $\mathrm{Z} 1$ \\
Time at Temperature & $60 \mathrm{~min}$ & $\mathrm{Z} 2$ \\
& $120 \mathrm{~min}$ & \\
Cooling Rate & $25^{\circ} \mathrm{C} / \mathrm{min}$ & \\
Table 4. Shallow Cryogenic Treatment Conditions & \\
\hline \hline & Parameters & Designation \\
\hline \hline Shallow cryogenic treatment & $77 \mathrm{~K}$ & $\mathrm{~N} 1$ \\
Temperature & liquid nitrogen & $\mathrm{N} 2$ \\
cooling medium & $60 \mathrm{~min}$ & \\
Time at Temperature & $120 \mathrm{~min}$ & \\
Cooling Rate & $36^{\circ} \mathrm{C} / \mathrm{min}$ & \\
\hline
\end{tabular}

The procedure applied for the below-zero treatment was as follows:

- oil quenched sintered steel samples were degreased by successive immersion in cold and hot benzene and then dried at $110{ }^{\circ} \mathrm{C}$ for the elimination of the infiltrated oil in pores during the oilquenching operation;

- cold treatment was carried out in a mixture of dry ice (solidified $\mathrm{CO}_{2}$ ) and technical alcohol;

- shallow cryogenic treatment was carried out in liquid nitrogen.

- oil quenched sintered steel samples were held in below-zero cooling mediums for 60, respectively $120 \mathrm{~min}$.

\section{RESULTS AND DISCUSSIONS}

The samples which are in the three stages of treatment are symbolized as follows:

$\mathrm{S}$ - as sintered at $\mathrm{t}=1150{ }^{\circ} \mathrm{C}$

$\mathrm{S}+\mathrm{OQ}$ - sintered and oil quenched 
$\mathrm{S}+\mathrm{OQ}+\mathrm{Z}$ - sintered, oil quenched and cooled in dry ice (Z1-60 min; Z2-120 min)

$\mathrm{S}+\mathrm{OQ}+\mathrm{N}$ - sintered, oil quenched and cooled in liquid nitrogen (N1-60 min; N2-120 min) For all samples the following characteristics have been determined:

- apparent density measured according to ISO 2738:1999;

- optical microscopy analysis according to ISO/TS 14321:1997;

- structural carbon $\mathrm{C}_{\mathrm{s}}$ in \%, (calculated by means of quantitative image analysis);

- content of constituents after cooling under zero;

- $\mu$ HRV 0,3 micro hardness measured according to ISO 4498:2010.

The series of micrographs in Fig. 1 depict the microscopic structure for the sintered samples with various carbon content and treated in the three above mentioned structural conditions ( $\mathrm{S}$ - as sintered; $\mathrm{S}+\mathrm{OQ}$ - sintered and oil quenched; $\mathrm{S}+\mathrm{OQ}+\mathrm{Z1}$ - sintered, oil quenched and cooled in dry ice for $60 \mathrm{~min}$; $\mathrm{S}+\mathrm{OQ}+\mathrm{Z} 2$ - sintered, oil quenched and cooled in dry ice for $120 \mathrm{~min}$; $\mathrm{S}+\mathrm{OQ}+\mathrm{N} 1$ sintered, oil quenched and cooled in liquid nitrogen for $60 \mathrm{~min}$; $\mathrm{S}+\mathrm{OQ}+\mathrm{N} 2$ - sintered, oil quenched and cooled in liquid nitrogen for $120 \mathrm{~min}$.

Table 5 gives the results of the quantitative image analysis applied in order to determine the amount of the various structural microconstituents identified in Fig.1 in the sintered steels in various structural conditions ( $\mathrm{F}=$ ferrite, $\mathrm{P}=$ perlite, $\mathrm{Cem}=$ cementite, $\mathrm{B}=$ bainite, $\mathrm{M}=$ martensite, $\mathrm{A}_{\text {ret }}=$ retained austenite). Error determination is $\sim 3 \%$.

Table 5. Results of the quantitative image analysis in the investigated sintered steels

\begin{tabular}{|c|c|c|c|c|c|c|c|c|c|c|}
\hline \multirow{2}{*}{$\begin{array}{c}\text { In-going } \\
\text { Graphite } \\
{[\%]}\end{array}$} & \multirow[b]{2}{*}{$\begin{array}{c}\text { Cs } \\
{[\%]}\end{array}$} & \multirow[b]{2}{*}{$\begin{array}{l}\text { Structural } \\
\text { condition }\end{array}$} & \multirow{2}{*}{$\begin{array}{c}\mathbf{F} \\
{[\%]}\end{array}$} & \multirow{2}{*}{$\begin{array}{c}\mathbf{P} \\
{[\%]}\end{array}$} & \multirow{2}{*}{$\begin{array}{l}\text { Cem } \\
{[\%]}\end{array}$} & \multirow{2}{*}{$\begin{array}{c}\mathbf{B} \\
{[\%]}\end{array}$} & \multicolumn{2}{|c|}{ Martensite } & \multicolumn{2}{|c|}{$\begin{array}{l}\text { Retained } \\
\text { austenite }\end{array}$} \\
\hline & & & & & & & $\begin{array}{c}\mathbf{M} \\
{[\%]}\end{array}$ & $\begin{array}{c}(+) \Delta \mathbf{M} \\
{[\%]}\end{array}$ & $\begin{array}{l}\mathbf{A}_{\text {ret }} \\
{[\%]}\end{array}$ & $\begin{array}{c}(-) \Delta \mathbf{A}_{\text {ret }} \\
{[\%]}\end{array}$ \\
\hline \multirow{6}{*}{0.6} & \multirow{6}{*}{0.54} & $\mathrm{~S}$ & 25.21 & 73.12 & - & - & - & - & - & - \\
\hline & & $\mathrm{S}+\mathrm{OQ}$ & 21.65 & 8.91 & - & 14.34 & 43.62 & - & 9.64 & - \\
\hline & & $\mathrm{S}+\mathrm{OQ}+\mathrm{Z1}$ & 20.52 & 8.74 & - & 14.08 & 48.76 & 11.78 & 5.93 & 16.86 \\
\hline & & $\mathrm{S}+\mathrm{OQ}+\mathrm{Z2}$ & 20.67 & 3.91 & - & 15.21 & 56.38 & 29.25 & 2.78 & 35.97 \\
\hline & & $\mathrm{S}+\mathrm{OQ}+\mathrm{N} 1$ & 17.50 & 3.16 & - & 14.23 & 63.12 & 44.70 & 1.98 & 79.46 \\
\hline & & $\mathrm{S}+\mathrm{OQ}+\mathrm{N} 2$ & 18.80 & 2.89 & - & 14.92 & 61.15 & 40.18 & 2.16 & 77.59 \\
\hline \multirow{6}{*}{0.8} & \multirow{6}{*}{0.75} & $\mathrm{~S}$ & 2.24 & 97.48 & - & - & - & - & - & - \\
\hline & & $\overline{S+O Q}$ & 2.08 & 11.16 & - & 18.19 & $\overline{55.31}$ & - & 11.54 & - \\
\hline & & $\mathrm{S}+\mathrm{OQ}+\mathrm{Z} 1$ & 2.13 & 4.48 & - & 17.25 & 67.16 & 21.42 & 8.81 & 23.63 \\
\hline & & $\mathrm{S}+\mathrm{OQ}+\mathrm{Z2}$ & 2.12 & 1.74 & - & 17.12 & 75.51 & 36.52 & 2.41 & 79.16 \\
\hline & & $\mathrm{S}+\mathrm{OQ}+\mathrm{N} 1$ & 2.21 & 2.13 & - & 11.48 & 82.12 & 53.26 & 1.15 & 90.03 \\
\hline & & $\mathrm{S}+\mathrm{OQ}+\mathrm{N} 2$ & 2.16 & 1.81 & - & 14.91 & 78.92 & 42.68 & 1.83 & 84.14 \\
\hline \multirow{6}{*}{1} & \multirow{6}{*}{0.92} & $\mathrm{~S}$ & - & 96.12 & 3.74 & - & - & - & - & - \\
\hline & & $\mathrm{S}+\mathrm{OQ}$ & - & 4.58 & 3.92 & 8.15 & 65.88 & - & 16.38 & - \\
\hline & & $\mathrm{S}+\mathrm{OQ}+\mathrm{Z1}$ & - & 4.12 & 3.87 & 8.41 & 74.14 & 12.53 & 7.92 & 51.64 \\
\hline & & $\mathrm{S}+\mathrm{OQ}+\mathrm{Z2}$ & - & 4.15 & 3.65 & 9.12 & 79.57 & 20.78 & 1.51 & 90.78 \\
\hline & & $\mathrm{S}+\mathrm{OQ}+\mathrm{N} 1$ & - & 1.11 & 3.63 & 4.15 & 86.63 & 31.49 & 1.48 & 90.96 \\
\hline & & $\mathrm{S}+\mathrm{OQ}+\mathrm{N} 2$ & - & 3.38 & 3.72 & 6.47 & 83.71 & 27.06 & 1.72 & 89.49 \\
\hline
\end{tabular}



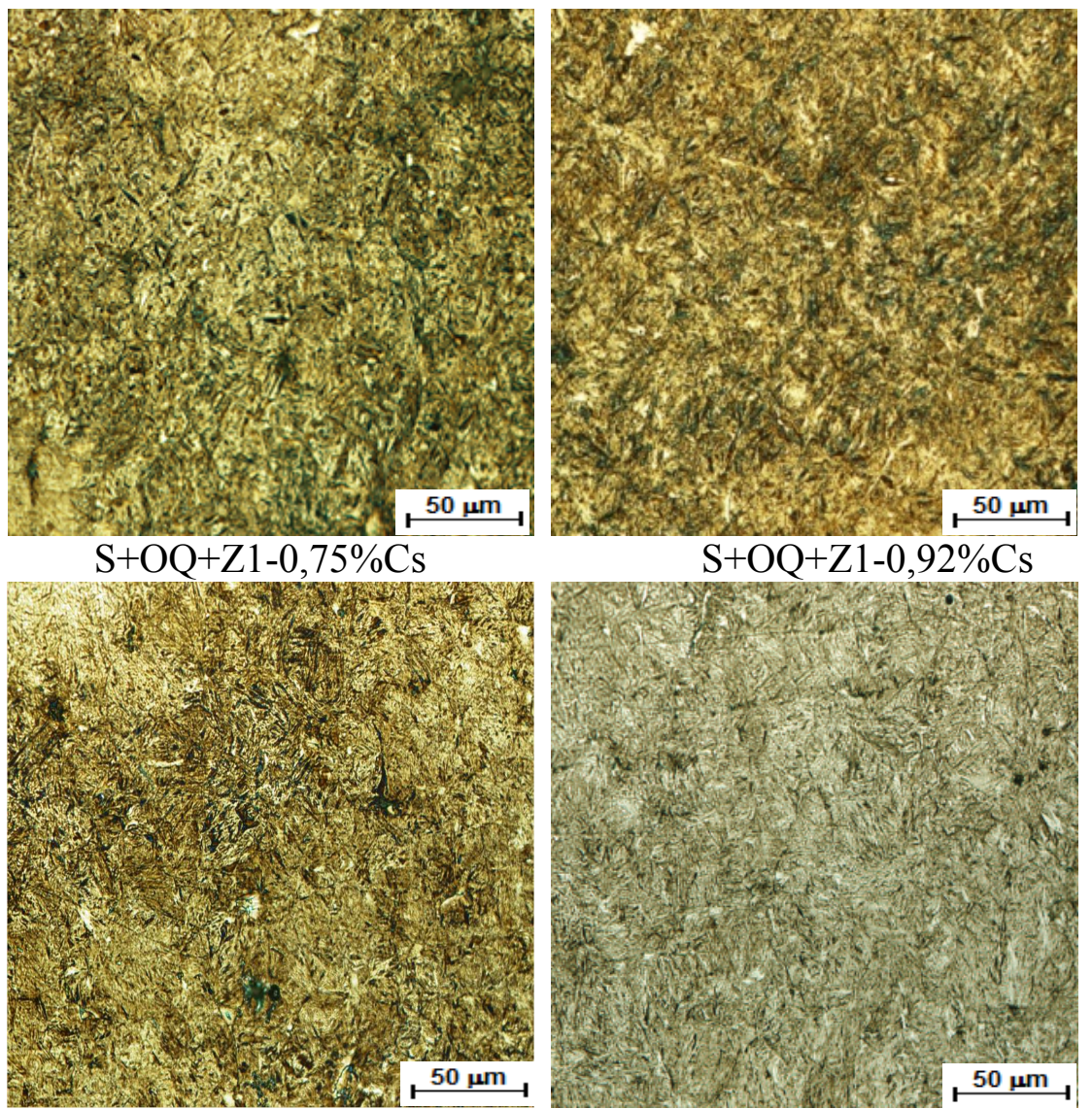

$\mathrm{S}+\mathrm{OQ}+\mathrm{Z} 1-0,92 \% \mathrm{Cs}$
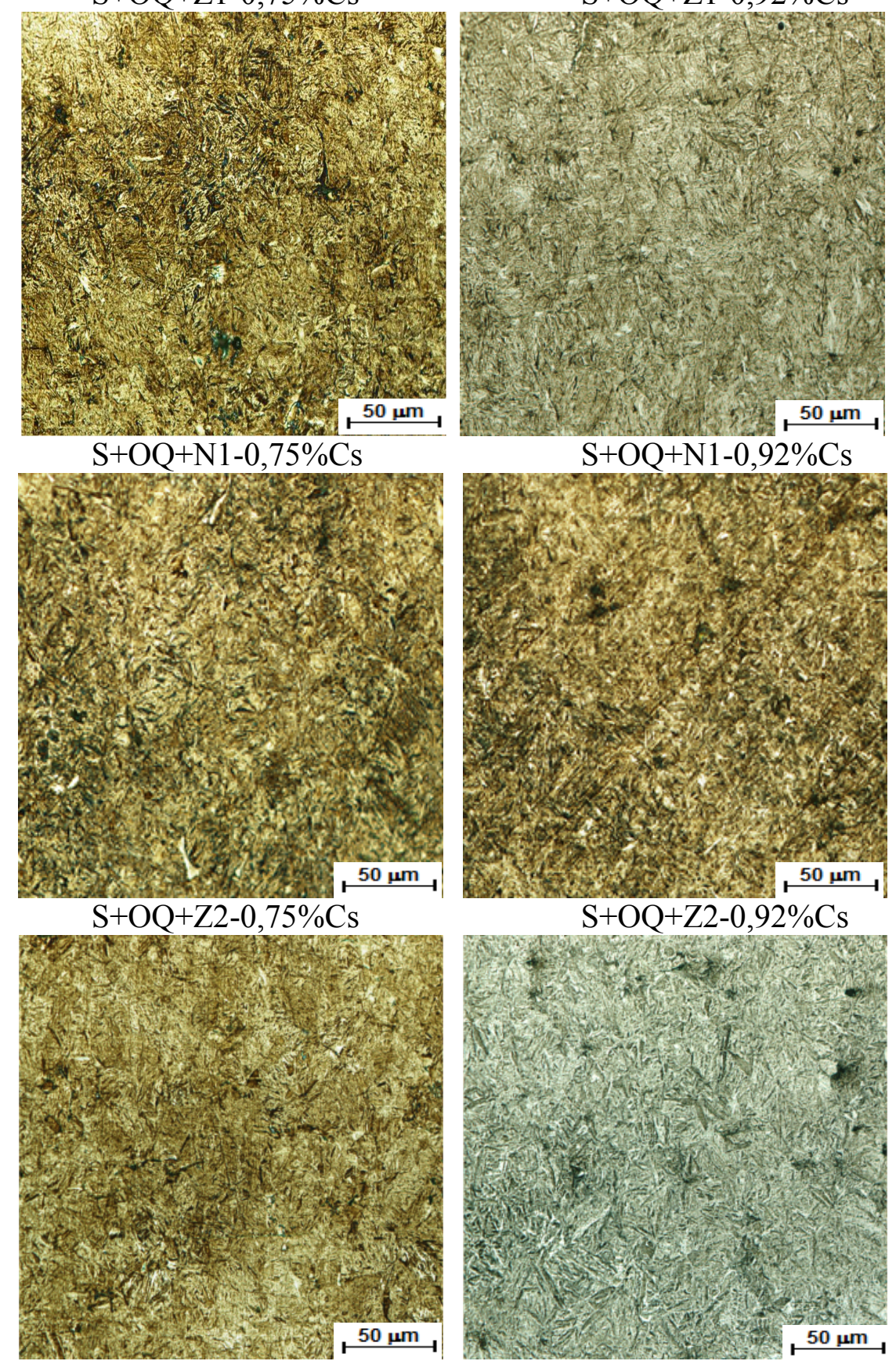

$\mathrm{S}+\mathrm{OQ}+\mathrm{N} 2-0,75 \% \mathrm{Cs}$

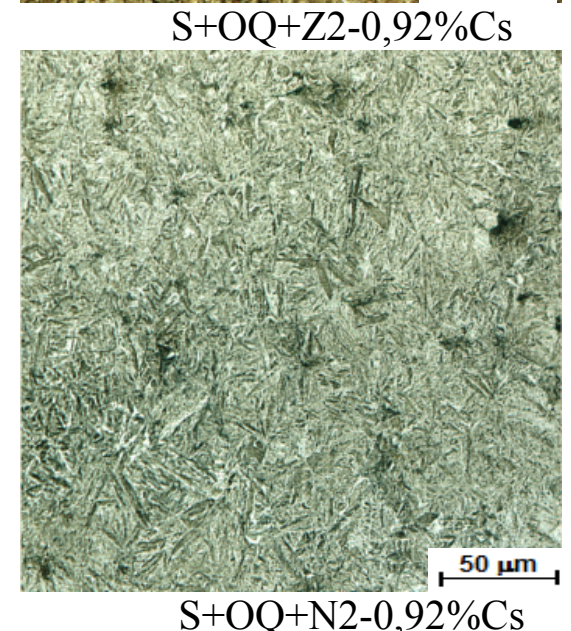

Fig.1. Microstructures of sintered steels samples etched with NITAL 2\% and PICRAL 2\% 
In Fig. 2 are shown comparative martensite phase and residual austenite phase in various stages of treatment of the steels, and in Fig. 3 are shown comparative the hardness values obtained in different stages of treatment of steels.

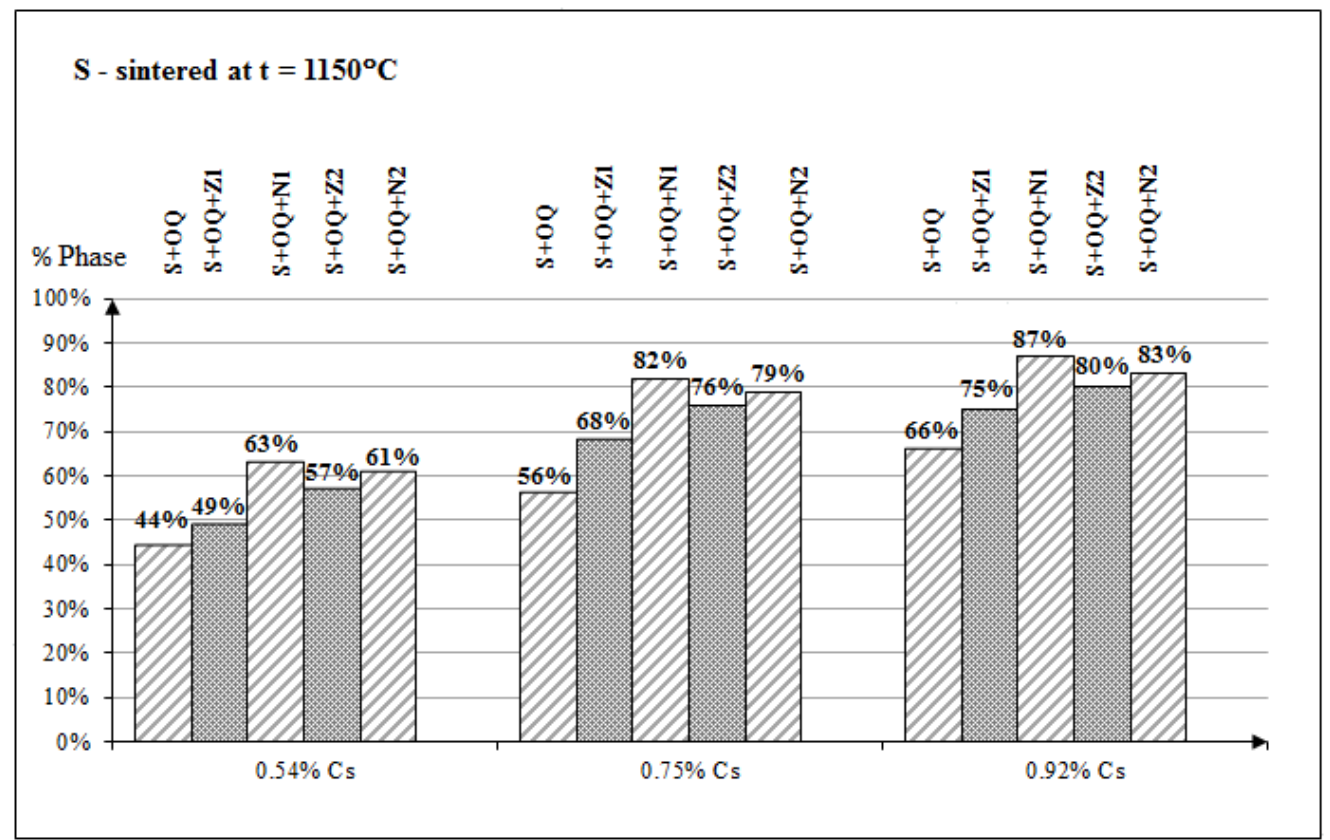

Fig.2. Percentages of hardening phases in sintered at $1150^{\circ} \mathrm{C}$, hardened and sub-zero cooled steels

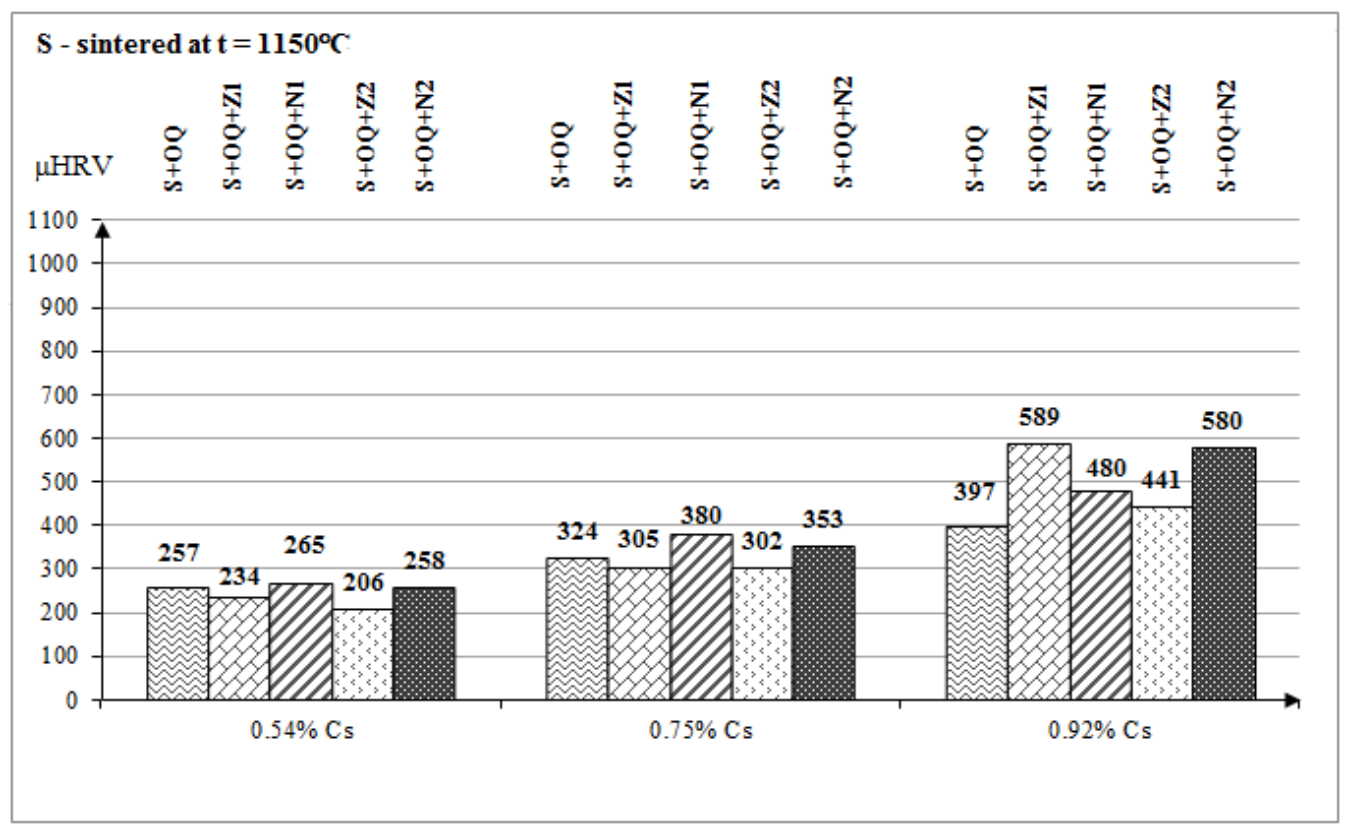

Fig.3. Micro hardness for the sintered at $1150{ }^{\circ} \mathrm{C}$, hardened and sub-zero cooled steels

The behavior at the sub-zero treatment of the sintered steels depends on the content of the structural carbon (Cs). Analysing the content of martensite after treatment at $197 \mathrm{~K}$ (cooled in dry ice) and $77 \mathrm{~K}$ (deep cryogenic treatment) it is found the following:

- In the case of steels hipoeutectoide $(\mathrm{C}=0.54 \% \mathrm{C})$ the treatment at high temperatures after quenching in oil do not have significant effects from the point of view of increase hardness although in case of this group of steels are produced the largest quantities of martensite through the transformation of residual austenite, but which has a low tetragonal martensite crystal structure. 
- In the case of hipoeutectoid sintered steels the cooling at low temperature after quenching in oil has more noticeable effects with how is increasing content of structural carbon (Cs), as can be seen from Fig. 2 and Fig. 3 for steels with $0.75 \%$ Cs and $0.92 \%$ Cs.

- In terms of the influence of the sub-zero treatment parameters on the sintered steel samples and quenched in oil give the following: the best results are obtained at cooling in liquid nitrogen maintaining it for $60 \mathrm{~min}$. ie in case of steels with $\mathrm{Cs}=0.92 \%$ occurs increasing the content of martensite with $32 \%$ and respectively of hardness with $31.81 \%$; in the case of the samples cooled in dry ice the best results are obtained for steels $\mathrm{Cs}=0.92 \%$ maintained for $120 \mathrm{~min}$ and namely martensite content that increase by $25 \%$ and hardness to $21 \%$.

\section{CONCLUSIONS}

In conclusion it can be said that sub-zero treatments applied to sintered steels after their tempering in oil are making felt its effects for contents of the structural carbon in the domain of the concentrations hipereutectoide.

If the cooling medium is deep cryogenic treatment is recommended a maintaining time reduced to 60 minutes, and if the cooling medium is the dry ice the maintaining times will be up to $120 \mathrm{~min}$.

\section{REFERENCES}

[1] Jun Wang, JiXiong, Hongyuan Fan, Hong-Shan Yang, Hao-Huai Liu, Bao-LuoShen, Effects of high temperature and cryogenic treatment on the microstructure and abrasion resistance of a high chromium cast iron. J. Mater. Process. Technol., (2009) vol. 209, pp. 3236 $\div 3240$,

[2] D. Senthilkumar, I. Rajendran, M. Pellizzari, Juha Siiriainen, Influence of shallow and deep cryogenic treatment on the residual state of stress of 4140 steel. J. Mater. Process. Technol., (2011) Vol.211, pp. $396 \div 401$,

[3] D. Das, K. K. Ray, A. K. Dutta, Influence of Temperature of Sub-Zero Treatments on the Wear Behaviour of Die Steel. Wear, Issue 9-10, (2009) Vol. 267, pp. 1361 $\div 1370$,

[4] Barron R.F, Cryogenic treatment of metals to improve wear resistance, Cryogenics, 22, (1982) pp 409-414

[5] P. I. Patil, R. G. Tated. Comparison of effects of cryogenic treatment on different types of steels: A review.http://research.ijcaonline.org/iccia/number9/iccia1068.pdf - 21 pages

[6] Mohan Lal D., Renganarayanan S., Kalanidhi A., Cryogenic treatment to augment wear resistance of tool and die steels, Cryogenics, 41, (2001) pp 149-155

[7] Seah KHW, Rahman M, Yong KH, Performance evaluation of cryogenically treated tungsten

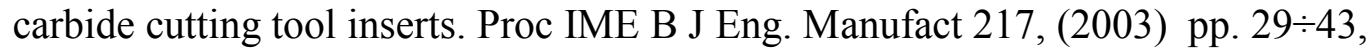

[8] Hemant B. Patil, Prashant B. Chavan, Shoeb H. Kazi, Effects of cryogenic on tool steels-a review, IJMPERD, Volume-1, Issue 1, (2013) pp 31-36

[9] Wayne Reitz, John Pendray, Cryoprocessing of materials: a review of current status. J. Mater. Manuf. Process,, vol. 16 (6), (2001) pp. 829-840

[10] Alexandru, Ailincai G, Baciu C., Influence ofcryogenic treatments on life of alloyed high speedsteels. Mem. Etud. Sci. Rev. Metall., 4, (1990) pp.203-6.

[11] Nirmal S. Kalsi, RakeshSehgal, and Vishal S. Sharma, Cryogenic Treatment of Tool Materials: $A$ Review Mater. Manuf. Process, 25, (2010) pp. 1077-1100,

[12] S. Dubovan, M. Demian, A.C. Calopereanu, L.Dubovan, Effects of sub-zero treatment aapplied to sintered steels. Newsletter Scientifically, UPB, Series B, Vol.76, Iss 1,(2014)pp. $187 \div 208$. 